\title{
Caffeine increases maximal fat oxidation during a graded exercise test: is there a diurnal variation?
}

\author{
Mauricio Ramírez-Maldonado ${ }^{2}$, Lucas Jurado-Fasoli ${ }^{1,2}$, Juan del Coso $^{3}$, Jonatan R. Ruiz ${ }^{2}$ and \\ Francisco J. Amaro-Gahete ${ }^{1,2^{*}}$ (D)
}

\begin{abstract}
Background: There is evidence that caffeine increases the maximal fat oxidation rate (MFO) and aerobic capacity, which are known to be lower in the morning than in the afternoon. This paper examines the effect of caffeine intake on the diurnal variation of MFO during a graded exercise test in active men.

Methods: Using a triple-blind, placebo-controlled, crossover experimental design, 15 active caffeine-naive men (age: $32 \pm 7$ years) completed a graded exercise test four times at seven-day intervals. The subjects ingested $3 \mathrm{mg} /$ $\mathrm{kg}$ of caffeine or a placebo at $8 \mathrm{am}$ in the morning and $5 \mathrm{pm}$ in the afternoon (each subject completed tests under all four conditions in a random order). A graded cycling test was performed. MFO and maximum oxygen uptake $\left(\mathrm{VO}_{2 \max }\right)$ were measured by indirect calorimetry, and the intensity of exercise that elicited MFO (Fat max $)$ calculated.

Results: MFO, Fat $\mathrm{max}_{\max }$ and $\mathrm{VO}_{2 \max }$ were significantly higher in the afternoon than in the morning (all $P<0.05$ ). Compared to the placebo, caffeine increased mean MFO by $10.7 \%(0.28 \pm 0.10 \mathrm{vs} .0 .31 \pm 0.09 \mathrm{~g} / \mathrm{min}$ respectively, $P<0.001)$ in the morning, and by a mean $29.0 \%(0.31 \pm 0.09$ vs. $0.40 \pm 0.10 \mathrm{~g} / \mathrm{min}, P<0.001)$ in the afternoon. Caffeine also increased mean Fat max $_{\text {m }}$ by $11.1 \%(36.9 \pm 14.4$ [placebo] vs. $41.0 \pm 13.1 \%, P=0.005)$ in the morning, and by $13.1 \%(42.0 \pm 11.6$ vs. $47.5 \pm 10.8 \%, P=0.008)$ in the afternoon.
\end{abstract}

Conclusion: These findings confirm the previously reported diurnal variation in the whole-body fat oxidation rate during graded exercise in active caffeine-naive men, and indicate that the acute ingestion of $3 \mathrm{mg} / \mathrm{kg}$ of caffeine increases MFO, Fat $t_{\max }$ and $\mathrm{VO}_{2 \max }$ independent of the time of day.

Trial registration: NCT04320446. Registered 25 March 2020 - Retrospectively registered

Keywords: Exercise performance, Body composition, Nutrition, Body weight, Dietary supplement

\footnotetext{
*Correspondence: amarof@ugr.es

${ }^{1}$ Department of Physiology. Faculty of Medicine, University of Granada, Av.

Conocimiento S/n, 18011 Granada, Spain

${ }^{2}$ PROFITH "PROmoting FITness and Health Through Physical Activity"

Research Group, Department of Physical Education and Sport, Faculty of

Sport Sciences, University of Granada, Granada, Spain

Full list of author information is available at the end of the article
}

C C The Author(s). 2021 Open Access This article is licensed under a Creative Commons Attribution 4.0 International License, which permits use, sharing, adaptation, distribution and reproduction in any medium or format, as long as you give appropriate credit to the original author(s) and the source, provide a link to the Creative Commons licence, and indicate if changes were made. The images or other third party material in this article are included in the article's Creative Commons licence, unless indicated otherwise in a credit line to the material. If material is not included in the article's Creative Commons licence and your intended use is not permitted by statutory regulation or exceeds the permitted use, you will need to obtain permission directly from the copyright holder. To view a copy of this licence, visit http://creativecommons.org/licenses/by/4.0/ The Creative Commons Public Domain Dedication waiver (http://creativecommons.org/publicdomain/zero/1.0/) applies to the data made available in this article, unless otherwise stated in a credit line to the data. 


\section{Introduction}

Endurance performance has been traditionally understood as a multifactorial concept in which maximal oxygen uptake $\left(\mathrm{VO}_{2 \max }\right)$, ventilatory thresholds and muscular efficiency play important roles [1]. Considerably less attention has been paid, however, to the importance of the management of substrate oxidation during prolonged exercise and its relationship with endurance performance [1]. Metabolic flexibility, known as the capacity to adapt fuel utilization to substrate availability, has recently been suggested an additional key factor affecting performance in endurance disciplines [2]. Given that maximal fat oxidation during a graded exercise test (MFO), and the intensity of exercise that elicits MFO (Fat ${ }_{\max }$ ), have been recognized as potential determinants of metabolic flexibility during exercise [3, 4], it seems plausible that both MFO and Fat ${ }_{\max }$ strongly influence endurance performance. Certainly, higher fat oxidation rates (at the expense of lower carbohydrate use) at moderate exercise intensities might help spare endurance athletes' muscle and liver glycogen stores during training and competition [5].

In athletes, it is known that endurance performance is poorer early in the morning and late at night compared with the afternoon [6], and that MFO and Fat max $_{\text {are }}$ higher in the afternoon compared to the morning whether in non-athlete male students [7], in untrained normalweight and obese individuals [8], or in endurance-trained athletes [9]. The difference has been explained by the higher body temperature, the enhanced neural activation and contractile properties of the skeletal muscle, and the higher plasma catecholamine concentrations found in response to exercise in the afternoon compared to the morning and evening $[10,11]$.

Caffeine is a natural alkaloid used by both endurance and resistance athletes as an ergogenic aid [12, 13]. It does not appear in the World Anti-Doping Agency's 2004 list of prohibited substances. Interestingly, the urine caffeine concentration recorded in doping control tests, especially for athletes of endurance-based sports, has increased progressively since it was removed from the above list [14]. Certainly, low-to-moderate doses of caffeine ( 3-9 mg/kg) [15] can increase endurance performance [16] via the induction of significant increases in $\mathrm{VO}_{2 \max }$, peak pulmonary ventilation, and muscle oxygen saturation during submaximal workloads [17, 18]. A recent study by Gutierrez-Hellín et al. [19] also shows caffeine ingestion to increase the MFO in healthy subjects of both sexes. Similarly, the ingestion of $5-7 \mathrm{mg} / \mathrm{kg}$ of caffeine during steady-state aerobic exercise seems to increase the utilization of fat as a fuel in detriment to the use of carbohydrate [20-22]. Preliminary reports also suggest that caffeine intake may help counteract the diurnal variation observed in exercise performance $[6,23-$
26]. Mora-Rodríguez et al. [24] reported that the acute ingestion of caffeine reverses the time-of-day reduction seen in maximum dynamic strength and muscle power output in resistance-trained men, while Boyett et al. [23] report that trained athletes are more likely to obtain ergogenic effects from caffeine in the morning than the evening (at least in terms of cycling performance). It would be of interest to know whether caffeine attenuates the diurnal variation seen in both the rate of whole-body fat oxidation during exercise, and in endurance performance, and whether caffeine has a synergistic effect with the already known diurnal variation in energy metabolism. The aim of the present work was, therefore, to investigate the effect of caffeine intake on the diurnal variation of MFO and Fat ${ }_{\max }$ during a graded exercise test in active men. Based on the available scientific literature, we hypothesised that: (i) The acute ingestion of caffeine will increase MFO, $\mathrm{Fat}_{\max }$ and $\mathrm{VO}_{2 \max }$ independent of the time of day. (ii) There will be a diurnal variation in $\mathrm{MFO}$, Fat $\mathrm{Fax}_{\max }$ and $\mathrm{VO}_{2 \max }$, with values being higher in the afternoon than in the morning.

\section{Methods \\ Subjects}

Fifteen active men, aged $32 \pm 7$ years, volunteered to participate in the current study (clinicaltrials.gov; NCT04320446). To be included all subjects had to: (i) have a body mass index of $18.5-28 \mathrm{~kg} / \mathrm{m}^{2}$, (ii) be non-smokers, (iii) suffer no disease that might be aggravated by physical exercise, (iv) take no medication or drugs, (v) be naive caffeine consumers $(<50$ $\mathrm{mg} /$ day), (vi) have previous experience in endurance training (i.e., self-reporting of at least 2 years of endurance training including three or more training sessions/week [3.6 \pm 0.2 sessions/week]), (vii) be free of any caffeine allergy, and (viii) have incurred no musculoskeletal injury during the previous month. All subjects were recruited by social networks and local media, and they provided oral and written informed consent before their enrolment. Procedures were performed in accordance with the latest revised Declaration of Helsinki (2013). The University of Granada Research Ethics Committee approved the present project ( $\mathrm{N}^{\circ} 507 / \mathrm{CEIH} / 2018$ ).

\section{Design and methodology}

This study had a triple-blind (i.e. participants, evaluation staff and statistician), placebo-controlled, crossover experimental design involving a graded exercise test performed by all subjects on four occasions, with each occasion separated by 7 days (Fig. 1). They were asked to maintain their physical activity levels and nutritional habits during the intervention. Subjects ingested either a dose of $3 \mathrm{mg} / \mathrm{kg}$ anhydrous caffeine in powder form (the extract of $\mathrm{HSN}^{\circ}$ green coffee beans [Harrison Sport Nutrition (HSN) Store, Granada, Spain]) or a $100 \%$ pure microcrystalline cellulose placebo [Acofarma, Madrid, 


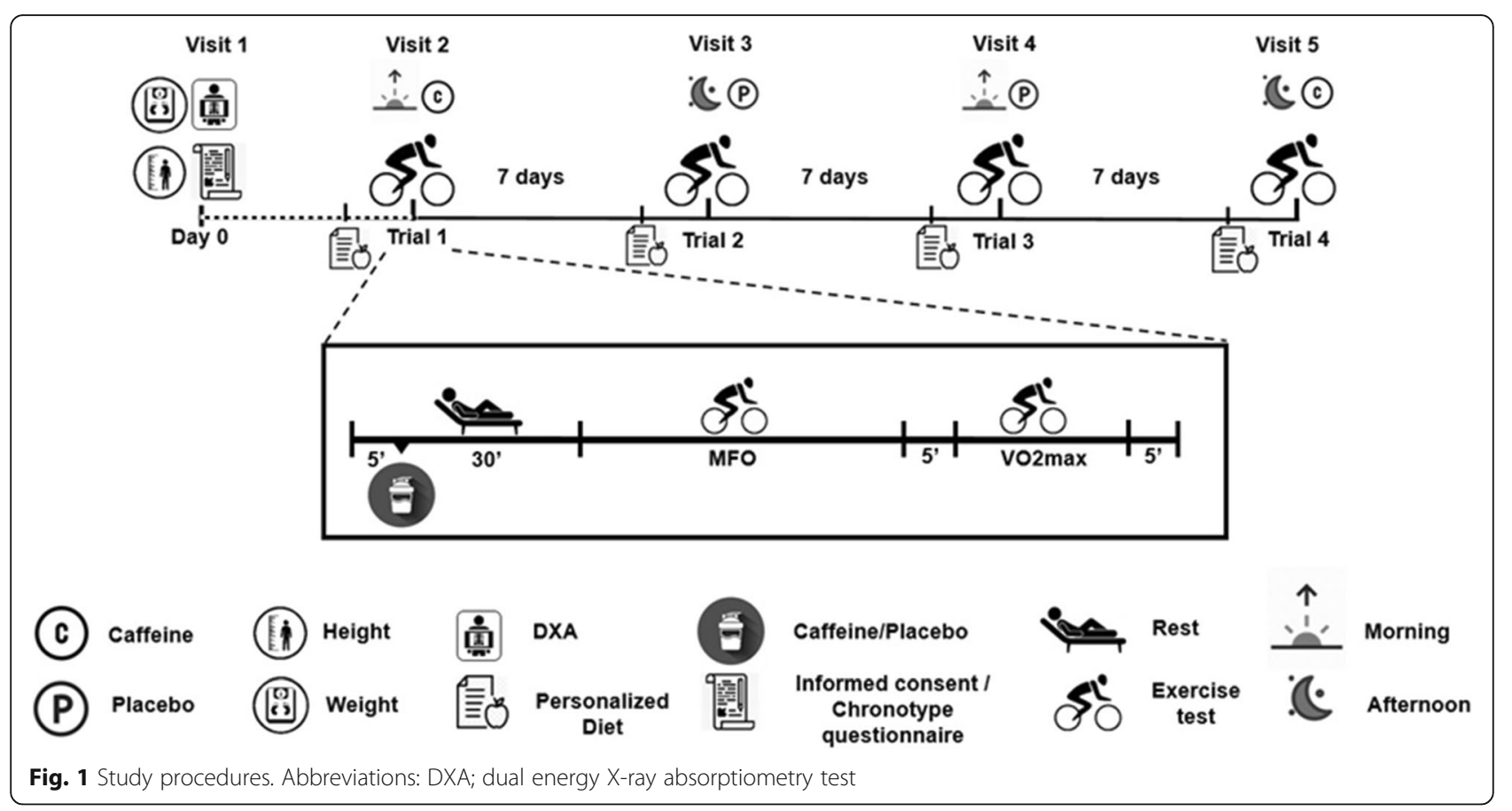

Spain]) 30 min before each test. Both supplements were unflavoured, uncoloured and odourless. The use of the above-mentioned dose was based on the results of previous studies reporting caffeine to be effective at increasing fat oxidation during exercise in trained athletes [19]. Both the caffeine and placebo were dissolved in $250 \mathrm{ml}$ of water and served in opaque, indistinguishable recipients; the subjects were therefore blind to what they had received.

The study was performed between June and November 2019. Measurements were conducted between 8 and 11 am (providing MFO-morning, Fat max $_{\text {-morning, and }}$ $\mathrm{VO}_{2 \max }$-morning), and between 5 and $8 \mathrm{pm}$ in the afternoon (providing MFO-afternoon, Fat ${ }_{\text {max }}$-afternoon, and $\mathrm{VO}_{2 \max }$-afternoon). The order of (i) the time of the day when the exercise tests were performed, and (ii) the administration of caffeine or placebo, were randomized using a function included in MS Excel for Windows ${ }^{\circ}$. However, all subjects were tested under all ingestion/ time-of-day condition combinations.

Before testing began (Day 0), subjects' weight and height were recorded using a Seca model 799 electronic column scale and stadiometer (Seca, Hamburg, Germany), and their body mass index calculated as weight divided by the square of the height $\left(\mathrm{kg} / \mathrm{m}^{2}\right)$. The body weight measured on this day was used in the dosage calculations for the entire experiment. Subjects were asked to be barefoot and to wear only light clothing during these measurements. Dual energy X-ray absorptiometry, performed using a Hologic Discovery Wii device (Hologic, Bedford, MA, USA), was conducted to determine subject lean and fat mass (kg). All subjects also completed the HÖME questionnaire to determine their chronotype (i.e., morningness-eveningness). They were subsequently categorized as (i) definite evening type (score range 16-30), moderate evening type (31-41), neither type (score 42-58), moderate morning type (5969) and definite morning type (70-86) [27]. Finally, all subjects were provided instructions: (i) to avoid moderate and vigorous physical activity 24 and $48 \mathrm{~h}$ respectively before test days, (ii) to adhere to a standardized, personalized diet (50\% carbohydrates, $30 \%$ fat and $20 \%$ protein) during the $24 \mathrm{~h}$ before each test day and to keep to the same meal order independent of the time of the day at which the test was performed, (iii) to arrive at the laboratory in a motorized vehicle to avoid physical activity, and (iv) to fast for 3 $\mathrm{h}$ before arrival. Compliance with these instructions was checked by self-reported dietary and exercise records.

On test days, a personalized dose of caffeine $(3 \mathrm{mg} / \mathrm{kg})$ or placebo was provided before performing the graded exercise test - undertaken using a Cardgirus Medical Pro cycle ergometer (C\&G Innovations, Cochin, India) under controlled environmental conditions (temperature: ranged from 22 to $24{ }^{\circ} \mathrm{C}$ and humidity: ranged from 40 to $50 \%$ ). After substance intake, subjects rested in the supine position for $30 \mathrm{~min}$ to ensure absorption. Thereafter, a submaximal graded exercise test was begun. This consisted of cycling at $50 \mathrm{~W}$ maintaining a cadence of 60-100 rpm for $3 \mathrm{~min}$ (warm-up protocol), with subsequent $25 \mathrm{~W}$ increments of the workload every $3 \mathrm{~min}$ until reaching a respiratory exchange ratio of $1.0[3,28]$. They then rested for $5 \mathrm{~min}$ with free access to water before beginning a maximal graded exercise test to 
measure their $\mathrm{VO}_{2 \max }$. This began with the same warmup protocol, followed by increments of $50 \mathrm{~W}$ every minute until self-reported exhaustion [29]. Indirect calorimetry data were registered using a CPX Ultima CardiO2 breath-by-breath gas analyzer (Medical Graphics Corp., St. Paul, MN, USA). A prevent ${ }^{\text {tm }}$ metabolic flow sensor (Medgraphics) fitted to a model 7400 oronasal mask (Hans Rudolph Inc., Kansas City, MO, USA) was used to obtain respiratory data. Simultaneously, a Polar RS800 heart-rate monitor (Polar Electro Inc., Woodbury, NY, USA) was used to monitor the heart rate during both maximal and submaximal graded exercise. The gas analyzer was calibrated immediately before each graded exercise, according to the manufacturer's recommendations.

\section{Submaximal graded exercise test}

The $\mathrm{VO}_{2}$ and $\mathrm{VCO}_{2}$ data derived from the last $60 \mathrm{~s}$ of each graded exercise stage were taken into account [30]. Fat oxidation rates were estimated from the stoichiometric equation of Frayn, assuming urinary nitrogen excretion to be negligible [31]. MFO and $\mathrm{Fat}_{\max }$ were determined by plotting fat oxidation values (dependent variable) against the relative exercise intensity (independent variable) to construct a third degree polynomial regression curve for each subject $(0,0)$ from a graphical depiction of fat oxidation values as a function of exercise intensity [32].

\section{Maximal graded exercise test}

The criteria for deeming $\mathrm{VO}_{2 \max }$ to have been reached were: (i) attaining a steady (increase $<2 \mathrm{ml} / \mathrm{kg} / \mathrm{min}$ ) in $\mathrm{VO}_{2}$ despite a further increase in workload, (ii) showing a maximal heart rate between $10 \mathrm{bpm}$ above and below the age-predicted maximum [33], and (iii) reaching a respiratory exchange ratio of $>1.1$ [34]. When these criteria were not met, peak oxygen consumption was taken into account (i.e., the highest $\mathrm{VO}_{2}$ value measured over the last $60 \mathrm{~s}$ of the test).

\section{Statistical analysis}

Sample size and power calculations were determined based on the results of a prior study [9]. We considered MFO differences between (i) morning vs. afternoon and (ii) caffeine vs. placebo test in order to assess the sample size requirements for the two-way analysis of variance (time-of-the day $\mathrm{x}$ substance). As a result, we expected to detect an effect size of $0.05 \mathrm{~g} / \mathrm{min}$ considering a type I error of 0.05 with a statistical power of 0.90 with a minimum of 12 participants. Assuming a maximum loss of $20 \%$, we decided to recruited a total of 15 participants. The results of every test were blindly introduced into the SPSS v.22.0 package (IBM Corporation, Pittsburgh, PA, USA); analyses were also performed blind to experimental conditions. Visual check histograms, Q-Q plots and Shapiro-Wilk tests were used to check the normality of all variables. Since all study outcomes were normally distributed, parametric tests were used to examine differences between conditions. Two-way analysis of variance (time-of-the day $x$ substance) was used to compare MFO, Fat ${ }_{\max }$ and $\mathrm{VO}_{2 \max }$ under different study conditions. When a significant $F$ value was obtained, a Bonferroni post hoc analysis was performed to determine pairwise differences. Additional analyses were conducted after adjusting for age, chronotype, lean mass and fat mass. Finally, experimental conditions with a common characteristic (i.e., morning vs. afternoon, and caffeine vs. placebo) were grouped to independently calculate the effect of the time of the day and substance provided on $\mathrm{MFO}$, Fat $\mathrm{max}_{\max }$ and $\mathrm{VO}_{2 \max }$ using pairwise tests. Significance was set at $P<0.05$. Lastly, we also calculated the standardized effect sizes using Cohen's d coefficients. Graphs were plotted using GraphPad Prism 5 (GraphPad Software, San Diego, CA, USA).

\section{Results}

Table 1 shows the characteristics of the study participants. The chronotype was homogeneously distributed ( $n=5$ moderate evening type, $n=5$ neither type, and $n=5$ moderate morning type).

Time-of-day had a significant effect on MFO $(P<$ 0.01 ), with the latter always higher (ranging from 10.7 to $29.0 \%$ ) in the afternoon than in the morning. Compared to the placebo, caffeine intake increased mean MFO by $10.7 \%$ in the morning $(0.28 \pm 0.10$ vs. $0.31 \pm 0.09 \mathrm{~g} / \mathrm{min}$ respectively, $P<0.001 ; \mathrm{d}=0.32$; Fig. 2 ) and by $29.0 \%$ in the afternoon $(0.31 \pm 0.09$ and $0.40 \pm 0.10 \mathrm{~g} / \mathrm{min}, P<$ $0.001 ; \mathrm{d}=0.95$; Fig. 2). A significant time-of-the day $x$ substance interaction was observed in MFO $(P<0.001$; Fig. 2).

Table 1 Characteristics of the study subjects $(n=15)$

\begin{tabular}{lccc}
\hline Age (years) & $\mathbf{3 2 . 4}$ & $\mathbf{\pm}$ & $\mathbf{7 . 2}$ \\
\hline Weight $(\mathrm{kg})$ & 79.9 & \pm & 10.7 \\
Height $(\mathrm{m})$ & 1.8 & \pm & 0.1 \\
Body mass index $\left(\mathrm{kg} / \mathrm{m}^{2}\right)$ & 25.6 & \pm & 2.3 \\
Fat mass (\%) & 18.5 & \pm & 3.9 \\
Lean mass (kg) & 61.7 & \pm & 9.0 \\
HÖME questionnaire score & & & \\
$\quad$ Definitive evening type $(\mathrm{n}[\%])$ & $0[0.0]$ & & \\
$\quad$ Moderate evening type $(\mathrm{n}[\%])$ & $5[33.3]$ & & \\
$\quad$ Neither type $(\mathrm{n}[\%])$ & $5[33.3]$ & & \\
$\quad$ Moderate morning type $(\mathrm{n}[\%])$ & $5[33.3]$ & & \\
$\quad$ Definite morning type $(\mathrm{n}[\%])$ & $0[0.0]$ & & \\
\hline
\end{tabular}

Values expressed as means \pm standard deviation 


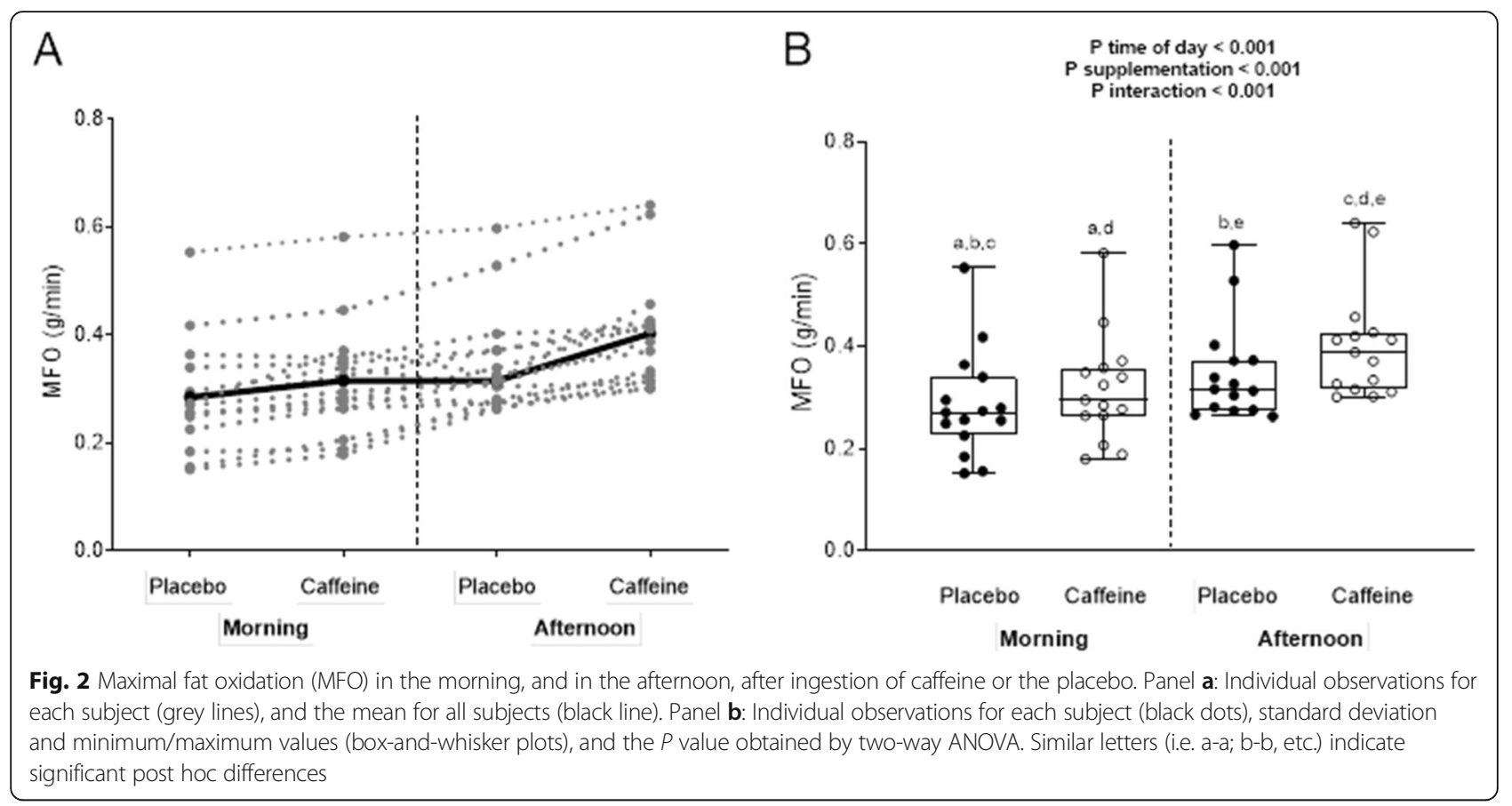

Time-of-day also had a significant effect on Fat ${ }_{\max }$ (all $P<0.01$ ), which was always higher (ranging from 11.1 to $13.1 \%)$ in the afternoon than in the morning. Compared to the placebo, caffeine intake increased $\mathrm{Fat}_{\max }$ by $11.1 \%$ in the morning $(36.9 \pm 14.4$ vs. $41.0 \pm 13.1 \%$ respectively; $\mathrm{d}=0.30$; Fig. 3 ) and by $13.1 \%$ in the afternoon $(42.0 \pm$ 11.6 vs. $47.5 \pm 10.8 \%$, respectively; $d=0.49$; Fig. 3 ). A strong trend toward significance time-of-the day $x$ substance interaction was observed in Fat ${ }_{\max }(P=0.058$; Fig. 3).

Finally, time-of-day had a significant effect on $\mathrm{VO}_{2 \max }$ $(P<0.05)$, which was always higher (ranging from 3.2 to $3.9 \%)$ in the afternoon than in the morning. Compared to the placebo, caffeine intake increased $\mathrm{VO}_{2 \max }$ by $3.9 \%$ in the morning $(43.7 \pm 7.8$ vs. $46.7 \pm 7.0 \mathrm{ml} / \mathrm{kg} / \mathrm{min}$, respectively; $\mathrm{d}=0.40$; Fig. 4 ) and by $3.2 \%$ in the afternoon

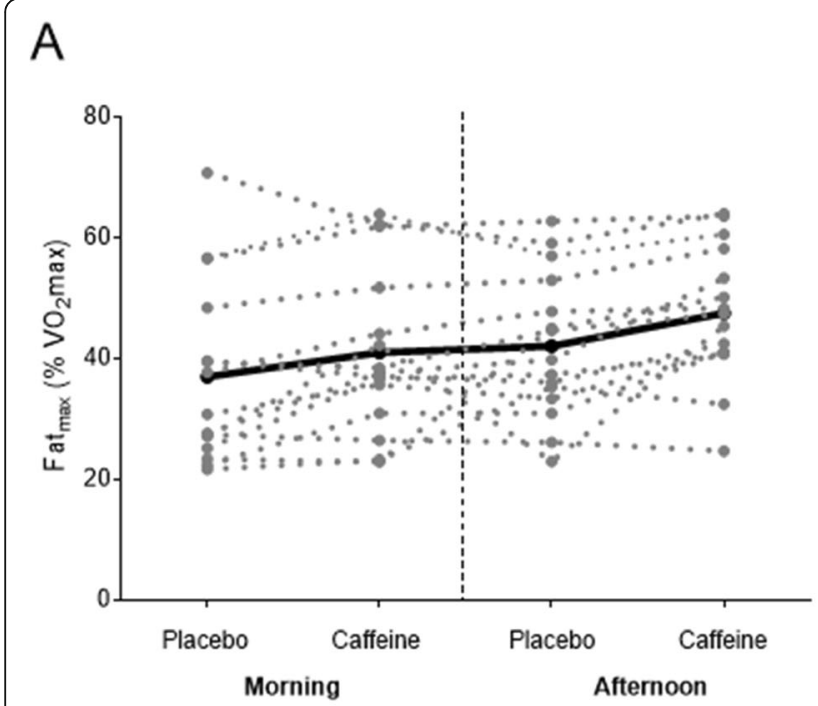

B

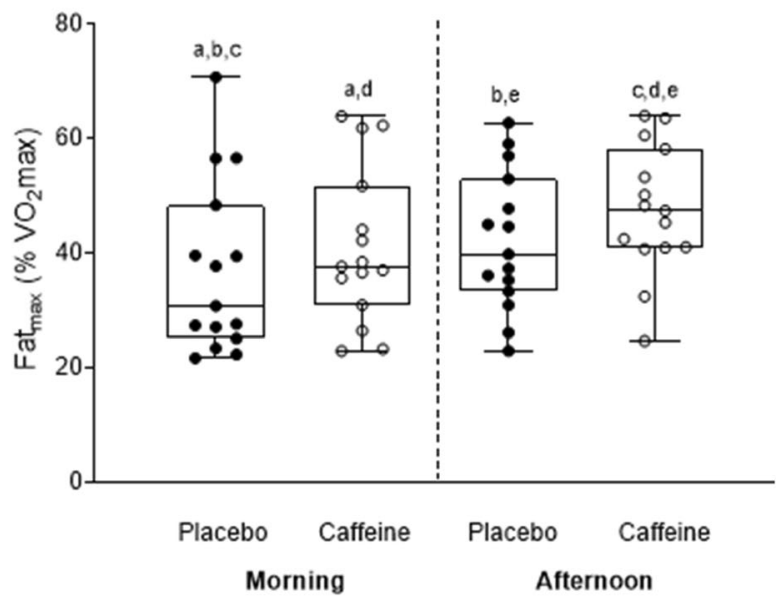

Fig. 3 Intensity of exercise eliciting maximal fat oxidation (Fat ${ }_{\max }$ ) in the morning, and in the afternoon, following the ingestion of caffeine or the placebo. Panel a: Individual observations for each subject (grey lines), and the mean for all subjects (black line). Panel b: Individual observations for each subject (black dots), standard deviation and minimum/maximum values (box-and-whisker plot), and the $P$ value obtained by two-way ANOVA. Similar letters (i.e., a-a; b-b, etc) indicate significant post hoc differences 


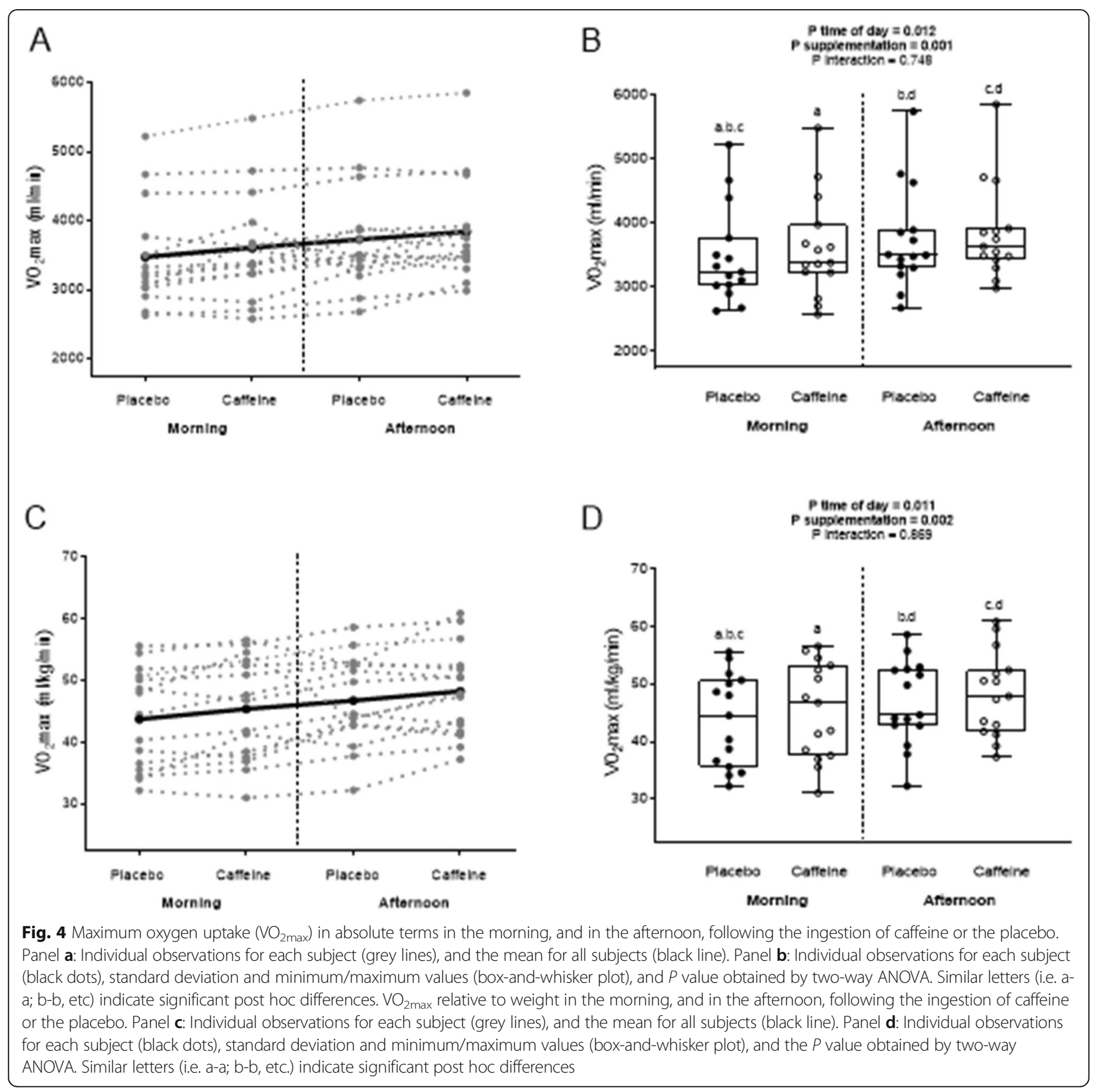

$(45.4 \pm 8.0$ vs. $48.2 \pm 7.0 \mathrm{ml} / \mathrm{kg} / \mathrm{min} ; \mathrm{d}=0.37$; Fig. 4$)$. No significant time-of-the day $x$ substance interaction was observed in $\mathrm{VO}_{2 \max }(P>0.7$; Fig. 4).

All the significant differences reported above persisted after adjusting for age, chronotype, lean mass and fat mass (data not shown).

\section{Discussion}

The present results indicate that caffeine intake increases MFO and Fat $t_{\max }$ as well as $\mathrm{VO}_{2 \max }$ independent of the time of day. The highest values for these variables were all obtained in the afternoon after caffeine intake. The results also show that, in the morning, the values of MFO after caffeine ingestion are nearly equivalent to those recorded in afternoon tests without caffeine supplementation. This suggests that caffeine increases whole-body fat oxidation during graded exercise in the morning to a value similar to that seen without caffeine in the afternoon. Overall, these results suggest that a combination of acute caffeine intake and exercise at moderate intensity in the afternoon provides the best scenario for individuals seeking to increase whole-body fat oxidation during aerobic exercise. 
Diurnal variation of MFO, Fat ${ }_{\max }$ and $\mathrm{VO}_{2 \max }$

The present findings provide further evidence regarding the diurnal variation of MFO and Fat ${ }_{\max }$, which have been reported higher in the afternoon than in the morning [7-9]. It should be noted that these previous studies were conducted using a treadmill graded exercise test to measure these variables. In the present work, a cycloergometer graded exercise test was used. Thus, together, these results suggest that the diurnal variations in MFO and Fat max $_{\max }$ are independent of subject characteristics and of the ergometer and protocol used to assess the whole-body fat oxidation rate during exercise. A number of studies have reported athletes to show better endurance performance during the afternoon than the early morning and late evening [10, 35], a finding with which the present results agree. However, in one study conducted in trained male athletes, no differences in $\mathrm{VO}_{2 \max }$ were seen between the morning and the afternoon [9]. With respect to this particular variable, the discrepancy might be explained by the different ergometers used (i.e., a cycloergometer in the present work, and a treadmill in the latter work), or the different biological characteristics of the study subjects, or the different fasting times before conducting the exercise test ( $3 \mathrm{~h}$ vs. $7-10 \mathrm{~h}$ respectively).

Endurance performance peaks in the afternoon usually coinciding with the highest core body temperature reached during the day [36]. This temperature increases energy metabolism, improves muscle compliance, and facilitates actin-myosin cross bridging [11]. Moreover, the exercise-induced catecholamine peak is higher in the afternoon than in the morning $[10,11]$. This catecholamine release promotes an increase in lipolysis in both skeletal muscle and adipose tissue [11,35], raising the plasma fatty acid content and explaining the higher fat oxidation rates observed in the afternoon. Since the present work collected no data on body core temperature or catecholamine release during exercise, further studies will be needed if these variables are to be better linked to the physiological mechanisms behind the observed diurnal variation in $\mathrm{VO}_{2 \max }$, MFO and Fat ${ }_{\max }$.

\section{Caffeine ingestion, MFO, $\mathrm{Fat}_{\max }$ and $\mathrm{VO}_{2 \max }$}

The results of the current study support the use of caffeine as an ergogenic aid to raise fat oxidation during exercise, as well as to increase $\mathrm{VO}_{2 \max }$, and agree with the findings of previous investigations showing that caffeine improves fuel oxidation during prolonged exercise [2022] and enhances endurance performance [12]. The present results also agree with those obtained by Gutiérrez-Hellín et al. [19] who reported $3 \mathrm{mg} / \mathrm{kg}$ caffeine to increase MFO in healthy active young men, as well as those reported by Dodd et al. [37] who indicate that 5 $\mathrm{mg} / \mathrm{kg}$ of caffeine improved $\mathrm{VO}_{2 \max }$ in naive caffeine consumers. The higher MFO, Fat ${ }_{\max }$ and $\mathrm{VO}_{2 \max }$ values recorded in the present work after caffeine ingestion may be explained by (i) an enhancement of fatty acid mobilization and oxidation, aided by an increase in the release of epinephrine, (ii) a blockage of the $A_{1}, A_{2 A}$, and $A_{2 B}$ adenosine receptors, thus promoting the release of acetylcholine and dopamine which dampens pain perception, blunts perceived exertion, and delays fatigue [16, 38-40], (iii) an increase in motor unit recruitment, which results in higher rates of muscular contraction and alertness [16], and/or (iv) an increase in muscle oxygen saturation that might facilitate the use of fat at moderate exercise intensities and lead to higher $\mathrm{VO}_{2}$ values at maximal exercise intensity [18].

\section{Effects of caffeine intake on the diurnal variation in MFO, Fat $_{\max }$ and $\mathrm{VO}_{2}$ max}

Mora-Rodríguez et al. [24] reported the acute ingestion of caffeine $(3 \mathrm{mg} / \mathrm{kg})$ to reverse the morning reduction in muscle performance - in fact to allow comparable muscle performance to those seen in the afternoon. These findings suggest that caffeine ingestion in the morning could be used by athletes as an ergogenic aid to help them avoid morning-induced reduction in muscle performance. In addition, Boyett et al. [23], who investigated whether the effect of caffeine on athletes' performance in a $3 \mathrm{~km}$ cycling time trial was influenced by the time of day and training status, concluded that caffeine enhanced cycling performance more in the morning than in the evening. These findings are partially in line with those of the present study, suggesting that acute caffeine intake before exercise serves as an effective ergogenic aid for reversing morning-induced reductions in resistance exercise performance and endurance-like performance.

The present study suffers from the limitation that body temperature and blood variable data were not collected during the graded protocol test, precluding any confirmation that metabolic and hormonal variables play a role in the diurnal variation of MFO, Fat $t_{\max }$ and/or $\mathrm{VO}_{2 \max }$. Moreover, we did not control the sleep quality and quantity of the participants. Further, the present study was performed in active men; the results cannot, therefore, be directly extrapolated to women or sedentary populations, etc. Finally, the sample size was relatively small.

\section{Practical applications}

- Caffeine intake increases MFO and Fat ${ }_{\max }$ as well as $\mathrm{VO}_{2}$ max independent of the time of day.

- The highest values for these variables were all obtained in the afternoon after caffeine intake.

- Caffeine increases MFO in the morning to a value similar to that seen without caffeine in the afternoon. 
- A combination of acute caffeine intake and exercise at moderate intensity in the afternoon provides the best scenario for individuals seeking to increase MFO.

\section{Conclusions}

In summary, the acute ingestion of caffeine $(3 \mathrm{mg} / \mathrm{kg})$ $30 \mathrm{~min}$ prior to a graded exercise test increased the $\mathrm{MFO}, \mathrm{Fat}_{\max }$ and $\mathrm{VO}_{2 \max }$ in active caffeine-naïve men independent of the time of day. Further, the existence of a diurnal variation in MFO, Fat ${ }_{\max }$ and $\mathrm{VO}_{2 \max }$ was confirmed, with values for all being higher in the afternoon than in the morning. The present findings also support the notion that caffeine ingestion in the morning helps to increase MFO and $\mathrm{Fat}_{\text {max }}$ levels during exercise in the afternoon. These results support the use of caffeine as an ergogenic aid during training or competition during the morning. The combination of acute caffeine intake and exercise at moderate intensity in the afternoon seems to be the best scenario for individuals seeking to increase the amount of fat utilized during continuous aerobic exercise. Whether higher doses of caffeine induce greater effects on whole-body fat oxidation during graded exercise tests and further improves endurance performance remains to be investigated.

\section{Abbreviations}

$\mathrm{VO}_{2 \text { max }}$ : Maximal oxygen uptake; MFO: Maximal fat oxidation during a graded exercise test; Fat $t_{\text {max }}$ Intensity of exercise that elicits maximal fat oxidation during exercise

\section{Acknowledgements}

We are grateful to Adrian Burton for language and editing assistance and to Harrison Sport Nutrition (HSN) store for its technical support.

\section{Authors' contributions}

MRM carried out the study procedures, and drafted the manuscript; LJF conceived of the study, discussed the results, revised the manuscript and approved the final version; JcC discussed the results, revised the manuscript and approved the final version; JRR conceived of the study, discussed the results, revised the manuscript and approved the final version; FAG conceived of the study, and participated in its design and coordination drafted the manuscript and revised and approved the final version.

\section{Funding}

This study was supported by the University of Granada Plan Propio de Investigación 2016-Excellence actions: Unit of Excellence on Exercise and Health (UCEES) and the Junta de Andalucía, Consejería de Conocimiento, Investigación y Universidades (ERDF: SOMM17/6107/UGR).

\section{Availability of data and materials}

The datasets used and/or analysed during the current study are available from the corresponding author on reasonable request.

\section{Ethics approval and consent to participate}

All subjects provided oral and written informed consent before their enrolment. Procedures were performed in accordance with the latest revised Declaration of Helsinki (2013). The University of Granada Research Ethics Committee approved the present project ( $\mathrm{N}^{\circ}$ 507/CEIH/2018).

\section{Consent for publication}

Not applicable.

\section{Competing interests}

The authors have no conflicts of interest to declare. The results of the study are presented clearly, honestly, and without fabrication, falsification, or inappropriate data manipulation.

\section{Author details \\ 'Department of Physiology. Faculty of Medicine, University of Granada, Av. Conocimiento S/n, 18011 Granada, Spain. ${ }^{2}$ PROFITH "PROmoting FITness and Health Through Physical Activity" Research Group, Department of Physical Education and Sport, Faculty of Sport Sciences, University of Granada, Granada, Spain. ${ }^{3}$ Centre for Sport Studies, Rey Juan Carlos University, Madrid, Spain}

Received: 13 July 2020 Accepted: 8 December 2020

Published online: 07 January 2021

\section{References}

1. Barnes KR, Kilding AE. Strategies to improve running economy. Sport Med. 2015;45:37-56 Available from: http://www.ncbi.nlm.nih.gov/ pubmed/25164465.

2. Fernández-Verdejo R, Bajpeyi S, Ravussin E, Galgani JE. Metabolic flexibility to lipid availability during exercise is enhanced in individuals with high insulin sensitivity. Am J Physiol Endocrinol Metab. 2018;315:E715-E722. Available from: https://www.physiology.org/doi/https://doi.org/10.1152/ ajpendo.00126.2018.

3. Maunder E, Plews DJ, Kilding AE. Contextualising maximal fat oxidation during exercise: determinants and normative values. Front Physiol. 2018:9:599.

4. Venables MC, Jeukendrup AE. Endurance training and obesity: effect on substrate metabolism and insulin sensitivity. Med Sci Sports Exerc United States. 2008:40:495-502.

5. Hearris M, Hammond K, Fell J, Morton J. Regulation of muscle glycogen metabolism during exercise: implications for endurance performance and training adaptations. Nutrients. 2018:10:298 Available from: http://www. mdpi.com/2072-6643/10/3/298

6. Souissi N, Bessot N, Chamari K, Gauthier A, Sesboüé B, Davenne D. Effect of time of day on aerobic contribution to the 30-s Wingate test performance. Chronobiol Int. 2007;24:739-48.

7. Darvakh H, Nikbakht M, Shakerian S, Sadat Mousavian A. Effect of Circadian Rhythm on Peak of Maximal Fat Oxidation on Non-Athletic Men. Zahedan J Res Med Sci. 2014;16:8-11.

8. Mohebbi $\mathrm{H}$, Azizi M. Maximal fat oxidation at the different exercise intensity in obese and normal weight men in the morning and evening. J Hum Sport Exerc. 2011;6:49-58.

9. Amaro-Gahete FJ, Jurado-Fasoli L, Triviño AR, Sanchez-Delgado G, De-la-O A, Helge JW, et al. Diurnal variation of maximal fat-oxidation rate in trained male athletes. Int J Sports Physiol Perform. 2019;14:1140-6.

10. Drust B, Waterhouse J, Atkinson G, Edwards B, Reilly T. Circadian rhythms in sports performance — an update. Chronobiol Int. 2005;22:21-44.

11. Teo W, Newton MJ, McGuigan MR. Circadian rhythms in exercise performance: implications for hormonal and muscular adaptation. J Sport Sci Med. 2011;10:600-6.

12. Grgic J, Mikulic P, Schoenfeld BJ, Bishop DJ, Pedisic Z. The influence of caffeine supplementation on resistance exercise: a review. Sport Med. 2019; 49:17-30.

13. Southward K, Rutherfurd-Markwick KJ, Ali A. The effect of acute caffeine ingestion on endurance performance: a systematic review and metaanalysis. Sport Med 2018;48:1913-1928. Available from: http://link.springer. com/https://doi.org/10.1007/s40279-018-0939-8.

14. Aguilar-Navarro M, Muñoz G, Salinero J, Muñoz-Guerra J, Fernández-Álvarez M, Plata M, et al. Urine caffeine concentration in doping control samples from 2004 to 2015. Nutrients. 2019;11:286 Available from: http://www.mdpi. com/2072-6643/11/2/286.

15. Grgic J, Grgic I, Pickering C, Schoenfeld BJ, Bishop DJ, Pedisic Z. Wake up and smell the coffee: caffeine supplementation and exercise performance_-an umbrella review of 21 published meta-analyses. $\mathrm{Br} \mathrm{J}$ Sports Med. 2019;bjsports-2018-100278. Available from: http://bjsm.bmj. com/lookup/doi/https://doi.org/10.1136/bjsports-2018-100278.

16. Goldstein ER, Ziegenfuss T, Kalman D, Kreider R, Campbell B, Wilborn C, et al. International society of sports nutrition position stand: caffeine and performance. J Int Soc Sports Nutr. 2010;7:1-15. 
17. Burke LM, Hawley JA. Swifter, higher, stronger: What's on the menu? Science. 2018;362:781-787. Available from: https://www.sciencemag.org/ lookup/doi/https://doi.org/10.1126/science.aau2093.

18. Ruíz-Moreno C, Lara B, Brito de Souza D, Gutiérrez-Hellín J, RomeroMoraleda B, Cuéllar-Rayo Á, et al. Acute caffeine intake increases muscle oxygen saturation during a maximal incremental exercise test. $\mathrm{Br} \mathrm{J}$ Clin Pharmacol. 2019;bcp.1418.

19. Gutiérrez-Hellín J, Del Coso J. Effects of p-Synephrine and caffeine ingestion on substrate oxidation during exercise. Med Sci Sport Exerc. 2018;50:1899906.

20. Schubert MM, Hall S, Leveritt M, Grant G, Sabapathy S, Desbrow B. Caffeine consumption around an exercise bout: effects on energy expenditure, energy intake, and exercise enjoyment. J Appl Physiol 2014;117:745-754 Available from: https://www.physiology.org/doi/https://doi.org/10.1152/ japplphysiol.00570.2014.

21. Anderson DE, Hickey MS. Effects of caffeine on the metabolic and catecholamine responses to exercise in 5 and 28 degrees C. Med Sci Sports Exerc, Available from. 1994;26:453-8 http://www.ncbi.nlm.nih.gov/pubmed/ 8201901.

22. Cruz R, de Aguiar R, Turnes T, Guglielmo L, Beneke R, Caputo F. Caffeine affects time to exhaustion and substrate oxidation during cycling at maximal lactate steady state. Nutrients. 2015;7:5254-64 Available from: http://www.mdpi.com/2072-6643/7/7/5219.

23. Boyett J, Giersch G, Womack C, Saunders M, Hughey C, Daley H, et al. Time of Day and training status both impact the efficacy of caffeine for short duration cycling performance. Nutrients. 2016;8:639. Available from: http:// www.mdpi.com/2072-6643/8/10/639.

24. Mora-Rodríguez R, Pallarés JG, López-Samanes Á, Ortega JF, Fernández-Elías VE. Caffeine ingestion reverses the circadian rhythm effects on neuromuscular performance in highly resistance-trained men. PLoS One. $2012 ; 7$.

25. Souissi $Y$, Souissi M, Chtourou $H$. Effects of caffeine ingestion on the diurnal variation of cognitive and repeated high-intensity performances. Pharmacol Biochem Behav, Available from. 2019;177:69-74 http://www.ncbi.nlm.nih. gov/pubmed/30611752.

26. Souissi M, Chtourou H, Abedelmalek S, Ben Gl, Sahnoun Z. The effects of caffeine ingestion on the reaction time and short-term maximal performance after 36h of sleep deprivation. Physiol Behav. 2014;131:1-6 Available from: https://inkinghub.elsevier.com/retrieve/pii/S0031938414002030.

27. Horne JA, Ostberg O. A self-assessment questionnaire to determine morningness-eveningness in human circadian rhythms. Int J Chronobiol. 1976;4:97-110

28. Amaro-Gahete FJ, Sanchez-Delgado G, Jurado-Fasoli L, De-la-O A, Castillo MJ, Helge JW, et al. Assessment of maximal fat oxidation during exercise: a systematic review. Scand J Med Sci Sports. 2019;sms.13424. Available from: https://onlinelibrary.wiley.com/doi/abs/https://doi.org/10.1111/sms.13424.

29. Frandsen J, Pistoljevic N, Quesada JP, Amaro-Gahete FJ, Ritz C, Larsen S, et al. Menstrual cycle phase does not affect whole body peak fat oxidation rate during a graded exercise test. J Appl Physiol. 2020;128:681-7.

30. Amaro-Gahete FJ, Sanchez-Delgado G, Alcantara JMA, Martinez-Tellez B, Acosta FM, Helge JW, et al. Impact of data analysis methods for maximal fat oxidation estimation during exercise in sedentary adults. Eur J Sport Sci. 2019;1-10. Available from: https://www.tandfonline.com/doi/full/https://doi. org/10.1080/17461391.2019.1595160.

31. Frayn KN. Calculation of substrate oxidation rates in vivo from gaseous exchange. J Appl Physiol. 1983;55:628-34 Available from: http://www.ncbi. nlm.nih.gov/pubmed/6618956.

32. Amaro-Gahete FJ, Sanchez-Delgado G, Helge JW, Ruiz JR. Optimizing maximal fat oxidation assessment by a treadmill-based graded exercise protocol: when should the test end? Front Physiol. 2019;10:909. Available from: https://www.frontiersin.org/article/https://doi.org/10.3389/fphys.2019. 00909/full.

33. Tanaka H, Monahan K, Seals D. Age-predicted maximal heart rate revisited. J Am Coll Cardiol. 2001;37:153-6.

34. Beltz NM, Gibson AL, Janot JM, Kravitz L, Mermier CM, Dalleck LC. Graded exercise testing protocols for the determination of VO 2 max: historical perspectives, Progress, and future considerations. J Sports Med. 2016;2016:1-12.

35. Atkinson G, Todd C, Reilly T, Waterhouse J. Diurnal variation in cycling performance: influence of warm-up. J Sports Sci. 2005;23:321-9.

36. Kim HK, Konishi M, Takahashi M, Tabata H, Endo N, Numao S, et al. Effects of acute endurance exercise performed in the morning and evening on inflammatory cytokine and metabolic hormone responses. PLoS One. 2015; 10:1-10.

37. Dodd SL, Brooks E, Powers SK, Tulley R. The effects of caffeine on graded exercise performance in caffeine naive versus habituated subjects. Eur J Appl Physiol Occup Physiol. 1991;62:424-9.

38. Doherty M, Smith PM. Effects of caffeine ingestion on rating of perceived exertion during and after exercise: a meta-analysis. Scand J Med Sci Sport. 2005;15:69-78.

39. LeBlanc J, Jobin M, Cote J, Samson P, Labrie A. Enhanced metabolic response to caffeine in exercise-trained human subjects. J Appl Physiol. 1985;59:832-7.

40. Ganio MS, Klau JF, Casa DJ, Armstrong LE, Maresh CM. Effect of caffeine on sport-specific endurance performance: a systematic review. J Strength Cond Res. 2009;23:315-24.

\section{Publisher's Note}

Springer Nature remains neutral with regard to jurisdictional claims in published maps and institutional affiliations.
Ready to submit your research? Choose BMC and benefit from:

- fast, convenient online submission

- thorough peer review by experienced researchers in your field

- rapid publication on acceptance

- support for research data, including large and complex data types

- gold Open Access which fosters wider collaboration and increased citations

- maximum visibility for your research: over $100 \mathrm{M}$ website views per year

At $\mathrm{BMC}$, research is always in progress.

Learn more biomedcentral.com/submissions 